\title{
The British Dental Editors Forum
}

Please send any ideas for feature articles for consideration to:

Rowena Milan,

British Dental Journal,

The Macmillan Building,

4-6 Crinan Street

London

N1 9XW

Email: r.milan@nature.com

Nairn Wilson

Chair, British Dental Editors Forum

In this short article, Nairn Wilson introduces the British Dental Editors Forum, a little-known but important organisation that provides support for dental editors and encourages quality and confidence in dental publications.

The British Dental Editors Forum (BDEF) is a little-known jewel in the crown of professional bodies and associations in UK dentistry. The Forum, as its title implies, provides opportunity for dental editors in the UK to meet to discuss issues of common interest and concern. Important as this is, given the considerable influence of UK-based dental editors, the Forum serves other significant functions. Of these other functions, encouraging quality and, in turn, confidence in dental publications stands out as the all-embracing raison d'etre of the Forum.

The Forum is inclusive, with membership being extended, free of any subscription, to all those involved in editing dental literature. Within the unclassified membership of the Forum, members range from editors-in-chief of international renown to all forms of commissioning and production editors, not to forget associate and section editors, let alone past editors and other supporters. The full spectrum of publications in dentistry is represented, spanning top-ranking, peer reviewed scientific journals to news letters of specialist associations and societies, whether commercial or simply a means of communication amongst groups of practitioners or other members of the dental team. As the current chairman of the Forum and keeper of the list of members, I am always pleased to receive and respond to expressions of interest in membership of the BDEF. Clearly, the larger and more inclusive the membership the better.

The activities of the Forum are not limited to meetings, comprising presentations and discussion on, for example, legal aspects of editing and publishing, processes to deal with the occasional miscreant author or other contributor and, of course, standards in dental publishing. Other activities of the Forum include networking nationally and internationally and, very importantly, support for individuals new to editing. Mercifully, it is not all work and no play. The Forum seeks opportunities for its members to interact socially and for the Forum to have a presence at major events in the dental calendar, including the British Dental Association (BDA) Annual Conference and Exhibition and meetings of the British Society for Dental Research. In general, editors need little encouragement to avail themselves of social intercourse. In fact, it is difficult to stop them doing what comes naturally - finding opportunity to communicate.

By way of a new initiative in 2007, the BDEF, generously supported by Henry Schein, hosted an event entitled 'Meet the editors'. This event, held in the BDA headquarters, brought together 31 editors and a galaxy of opinion leaders and senior representatives of the major organisations in UK dentistry. An added bonus to the highly successful venture was the raising of $£ 3,250$ to be donated in equal amounts to the BDA Benevolent
Fund and the Oral and Dental Research Trust. In addition to the support of Henry Schein and the help of the BDA, the success of the event was, in no small measure, down to the outstanding generosity of a number of organisations, notably Blackwell Publishing Limited, the British Dental Trade Association, Davis Schottlander \& Davis Limited, Denplan Limited, the Dental Practitioners' Association and Plandent Limited.

The BDEF has enjoyed considerable success, and will hopefully serve good purpose in the years to come. A great deal is expected of editors and members of editorial teams, many of whom receive little, if any, reward for their efforts. Indeed, given that part of the standing of a profession is the quality of its literature, it could be argued that dental editors shoulder a special responsibility in maintaining and wherever possible strengthening dentistry in modern healthcare provision and related sciences. The BDEF provides a platform to help editors and their editorial teams to fulfil this responsibility both individually and collectively. As such, the BDEF must endure the challenge of being part of the bedrock on which the profession can continue to build and flourish - a worthy mission for any professional organisation.

DOI: 10.1038/sj.bdj.2008.251 